\title{
Correction: p63 $\alpha$ modulates c-Myc activity via direct interaction and regulation of MM1 protein stability
}

\section{Anning Han, Juan Li, Yimin Li, Yang Wang, Johann Bergholz, Yujun Zhang, Chenghua Li, Zhi-Xiong Xiao}

Copyright: Han, et al. This is an open-access article distributed under the terms of the Creative Commons Attribution License (CC-BY), which permits unrestricted use, distribution, and reproduction in any medium, provided the original author and source are credited.

Present: In the title and abstract, the ' $\beta$ ' symbol was mistakenly inserted instead of ' $\alpha$ '.

\section{p63 $\beta$ modulates c-Myc activity via direct interaction and regulation of MM1 protein stability}

\section{Anning Han ${ }^{1}$, Juan $\mathrm{Li}^{1,}{ }^{*}$, Yimin $\mathrm{Li}^{1,}{ }^{*}$, Yang Wang ${ }^{1}$, Johann Bergholz ${ }^{1}$, Yujun Zhang ${ }^{1}$, Chenghua Li ${ }^{1}$ and Zhi-Xiong Xiao ${ }^{1}$}

This article corrects: p63 $\beta$ modulates c-Myc activity via direct interaction and regulation of MM1 protein stability, Volume 7, Issue 28, 44277-44287. Article first published online: 2016 Jun 20.

Link of original article: https://www.ncbi.nlm.nih.gov/pmc/articles/PMC5190095/

doi: $10.18632 /$ oncotarget.10187

Correct: The proper title and abstract appear below.

The title should read

\section{p63 $\alpha$ modulates c-Myc activity via direct interaction and regulation of MM1 protein stability}

All symbols of " $\beta$ " in the ABSTRACT should be changed into " $\alpha$ ".

\begin{abstract}
Both p53-related p63 and c-Myc are transcription factors playing key roles in cell proliferation, survival, development and tumorigenesis. In the present study, we identified that MM1, a c-Myc inhibitor, specifically binds to C-termini of p63 $\alpha$ (including $\Delta \mathrm{Np} 63 \alpha$ and TAp63 $\alpha$ ). Further study demonstrates that $\mathrm{p} 63 \alpha$ facilitates MM1 protein degradation via proteasomal pathway, resulting in elevation of c-Myc transactivation activity. Knockdown of $\Delta$ Np63 $\alpha$ leads to decrease in c-Myc protein levels, concomitant with reduced expression of CDK4 and Cyclin D1, and impaired cell cycle progression, both of which are effectively reversed by simultaneous knockdown of MM1. Moreover, expression of p63 and CDK4 is concomitantly upregulated in B-cell acute lymphoblastic leukemia. Together, this study reveals a novel crosstalk between p63 and c-Myc that may play an important role in cell cycle progression and tumorigenesis.
\end{abstract}

Original article: Oncotarget. 2016; 7:44277-44287. doi: 10.18632/oncotarget.10187 